\title{
Phase-field modelling of microstructure evolution during processing of cold-rolled dual phase steels
}

\author{
Jenny Rudnizki, Ulrich Prahl* and Wolfgang Bleck
}

\author{
* Correspondence: ulrich.prahl@iehk \\ rwth-aachen.de \\ Department of Ferrous Metallurgy, \\ IEHK, RWTH Aachen University, \\ Intzestr 1, 52056, Aachen, Germany
}

\begin{abstract}
Cold-rolled dual-phase steels, which belong to the advanced high strength steels, have gained much interest within the automotive industry. The formation of dualphase microstructure, which provides an optimal combination of strength and formability for automotive applications, occurs during intercritical annealing of coldrolled strip. Variations in the chemical composition as well as in the heat treatment parameters influence very strongly the microstructure development and therefore the final mechanical properties of the strip. Thus, the precise control of the microstructure evolution during full processing route is required for the achievement of essential mechanical properties. The current work is focused on a through-process model on a microstructural scale for the production of dual-phase steel from coldrolled strip, which is based on Phase-Field Method and combines the description of ferrite recrystallisation and all phase transformations occurring during intercritical annealing. This approach will enable the prediction of final microstructure for varying composition and processing conditions, and therefore, can be used for the process development and optimisation.
\end{abstract}

Keywords: Phase-field modelling, Phase transformation, Dual-phase steels

\section{Background}

The mechanical properties of dual-phase steels are provided by a microstructure which consists of two different phases with different hardness, i.e. hard martensitic islands in a soft ferrite matrix. Thereby, not only phase fractions but also distribution and morphology of both phases are responsible for the mechanical properties $[1,2]$. The formation of dual-phase microstructure from cold-rolled strip occurs during intercritical annealing which involves different metallurgical phenomena, like recrystallisation and phase transformations [3,4]. Each of these processes contributes to the establishment of the final microstructure. Thus, the control of the microstructure evolution during the whole processing of dual-phase steels is therefore the key for the processing of steels with predetermined mechanical properties. Therefore, several detailed experimental studies of DP microstructure evolution have been performed e.g. [5-7].

Beside of that, the numerical investigation which is an alternative to complex and expensive experiments can be very helpful. Nowadays, computational materials science is a powerful approach for understanding physical mechanisms and their interactions during industrial processing allowing the prediction of microstructure as well as of

(c) 2012 Rudnizki et al.; licensee Springer. This is an Open Access article distributed under the terms of the Creative Commons Attribution License (http://creativecommons.org/licenses/by/2.0), which permits unrestricted use, distribution, and reproduction in any medium, provided the original work is properly cited. 
mechanical properties [8,9]. It can be applied for the improvement of process parameters and optimisation of chemical composition.

Up to now, different mechanisms along the annealing route of cold-rolled strips in dual-phase processing, as there are recrystallization in cold formed ferrite, austenite formation, grain growth in ferrite and austenite, formation of ferrite and martensite, have been investigated separately. However, the current trend in computational materials science moves towards ICME (Integrative Computational Materials Engineering) where individual approaches on the different scales are combined in order to describe a process chain completely $[10,11]$. Such combination of models describing single process steps allows the prediction of final product properties from the knowledge of chemical composition and processing conditions.

At the time, no through-process model for the processing of dual-phase steels, which covers all metallurgical phenomena on a microstructural scale in one integral approach, is available. Setting up such through-process model is expected to lead to significant improvement in the prediction of microstructure development and therefore, to enable robust production of dual-phase steels with predefined mechanical properties. Hereby, the Phase-Field approach represents a powerful method for the calculation of microstructure evolution in multi-phase multicomponent systems which can be applied to the establishment of through-process model. The potential and ability of this approach for the prediction of several phase transformations have been already show in many works [12-15].

The main focus of this work is the formulation of a through-process model on a microstructural scale for the production of dual-phase steels from cold-rolled strip by means of Phase-Field approach. 2D- and 3D-simulation results of the microstructure evolution during intercritical annealing will be shown and compared to experimental results.

\section{Methods}

\section{Experimental}

\section{Material characterisation}

The material used in this study is industrially produced cold-rolled steel sheet of $1 \mathrm{~mm}$ thickness and $60 \%$ cold rolling reduction. The chemical composition of the steel is listed in Table 1. As in a typical DP-steel, the main alloying elements are $\mathrm{C}, \mathrm{Si}, \mathrm{Mn}$, and $\mathrm{Cr}$.

According to metallographic analysis, the initial microstructure of investigated material consists of two phases: the bright ferrite matrix and dark pearlite grains, Figure 1 . Both types of grains have an elongated shape, due to cold-rolling. The average pearlite content was determined to be $16 \%$ by means of image analysis. In order to determine the distribution of the alloying elements in the initial structure, a microprobe (ESMA) analysis was performed. The concentration of $\mathrm{C}, \mathrm{Si}, \mathrm{Mn}$, and $\mathrm{Cr}$ was measured along the arrow in the zone between two indents that were used to mark the selected area.

Table 1 Chemical composition (in wt.-\%) of the investigated steel

\begin{tabular}{ccccccccccc}
\hline $\mathbf{C}$ & $\mathbf{S i}$ & $\mathbf{M n}$ & $\mathbf{P}$ & $\mathbf{S}$ & $\mathbf{C r}$ & $\mathbf{A l}$ & $\mathbf{N}$ & $\mathbf{N b}$ & $\mathbf{T i}$ & $\mathbf{V}$ \\
\hline 0.098 & 0.24 & 1.65 & 0.017 & 0.007 & 0.55 & 0.04 & 0.004 & 0.001 & 0.002 & 0.008 \\
\hline
\end{tabular}




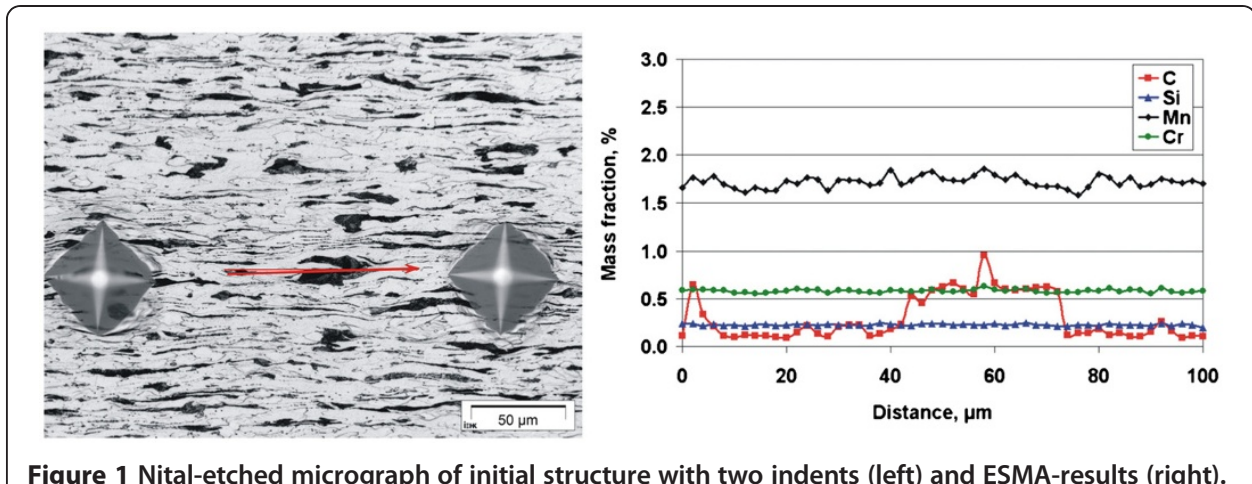

According to the microprobe analysis, carbon concentration of pearlite is about 0.60 wt.-\%. In parallel, Thermo-Calc ${ }^{\circledR}$ calculations were performed taking into account C, $\mathrm{Si}, \mathrm{Mn}$ and $\mathrm{Cr}$. This confirms as well the eutectic concentration of investigated steel at approximately 0.60 wt.- $\%$ of carbon. The $\mathrm{C}$ concentration in ferrite is much lower. However, the exact determination of the carbon content in ferrite by means of microprobe analysis is limited due to the very small concentration. No difference was found between the concentrations of $\mathrm{Si}, \mathrm{Mn}$ and $\mathrm{Cr}$ in ferrite and pearlite in the initial structure: the content of the substitutional elements in both phases is equal to the total content in the steel. Thus the initial structure contains $16 \%$ of pearlite with 0.60 wt.- $\% \mathrm{C}$, 0.24 wt.-\% Si, 1.65 wt.-\% $\mathrm{Mn}$, and 0.55 wt.-\% $\mathrm{Cr}$ in a ferritic matrix with the same content of substitutional elements. Knowing the carbon content and phase fraction of pearlite, the carbon concentration in ferrite was calculated to be $0.002 \mathrm{wt.}$. $\%$ using total carbon content and mass balance.

The stored energy distribution, which is also an important characteristic of material, was obtained based on EBSD analysis assuming that the misorientations within deformed grains reflect the distribution of a small angle grain boundary and therefore, the stored energy. The approach to identify the stored energy from misorientation maps has been developed by Zaefferer and can be found at $[16,17]$. The average value of the stored energy for the investigated steel was evaluated to be $4.5 \mathrm{~J} / \mathrm{cm}^{3}$. Additionally, the EBSD analysis is applied in this work for the determination of ferrite grain size distributions.

\section{Experimental process simulation}

In order to investigate the microstructure evolution during intercritical annealing, tests were performed on Baehr Dilatometer DIL-805A/D. For these experiments, the samples with $1 \mathrm{~mm}$ thickness, $4 \mathrm{~mm}$ width and $8 \mathrm{~mm}$ length were cut parallel to the rolling direction of the ingot. The dilatometric tests have been carried out with a dilatometer type DIL-805A/D fabricated by Baehr Thermoanalyse GmbH. Experiments were realised by a low-pressure environment of the order of $10^{-5} \mathrm{MPa}$ in order to protect the samples from oxidation. During experiments temperature was recorded by a thermocouple. Figure 2 represents intercritical heat treatment performed in dilatometer which corresponds to a simplified industrial processing of dual-phase steel. According to this heat treatment, the samples were heated in two-steps to the intercritical temperature of $800^{\circ} \mathrm{C}$, held $60 \mathrm{~s}$ at $800^{\circ} \mathrm{C}$ and afterward cooled down slowly with $1^{\circ} \mathrm{C} / \mathrm{s}$ to $600^{\circ} \mathrm{C}$.

Along the intercritical heat treatment samples were quenched at various stages as can be found in Figure 2 using a helium atmosphere. Thus, the microstructure at the 


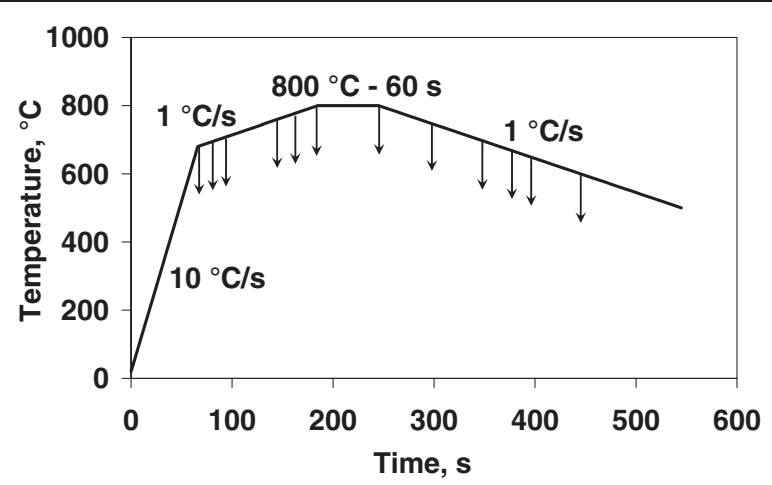

Figure 2 Intercritical heat treatment processed in dilatometer; at various stages process was interrupted by quenching in order to freeze the microstructure.

chosen temperatures was frozen and afterwards studied by means of light optical microscopy. The corresponding average values of the ferrite fraction were obtained by an image analyser of four nital-etched micrographs per sample at magnification 1000x.

\section{Modelling}

Multicomponent multiphase-field approach

The Phase-Field approach is developed for the modelling of the phase transformations in multicomponent systems [18-20]. For simulation work in this paper the commercial software package MICRESS ${ }^{\circledR}$ is used which allows the calculation of phase fractions during solid-solid transformations in multicomponent steels as well as the description of the corresponding microstructure evolution [21].

Multiphase-Field is a computational approach which describes the evolution of multiple Phase-Field parameters $\varphi_{i}(\rightarrow x, t)$ in time and space. These fields map the spatial distribution either of different grains with different stored energy or of phases with different thermodynamic properties. At the interfaces, the Phase-Field variables change continuously between 0 and 1 over an interface thickness $\eta$ which can be chosen to be large compared to the atomic interface thickness, but small compared to the microstructure length scale. The time evolution of the phases is calculated by a set of PhaseField equations formulated by minimization of the free energy functional [19]:

$$
\begin{aligned}
& \dot{\varphi}_{i}=\sum_{j} M_{i j}(\vec{n})\left(\sigma_{i j}^{*}(\vec{n}) K_{i j}+\frac{\pi}{\eta} \sqrt{\varphi_{i} \varphi_{j}} \Delta G_{i j}(\vec{c}, T)\right) \\
& K_{i j}=\varphi_{j} \nabla^{2} \varphi_{i}-\varphi_{i} \nabla^{2} \varphi_{j}+\frac{\pi^{2}}{\eta^{2}}\left(\varphi_{i}-\varphi_{j}\right)
\end{aligned}
$$

In Eq. (1), $i j$ is the mobility of the interface as a function of the interface orientation, given by the normal vector $\mathrm{n} \rightarrow \sigma_{i j}^{*}$ is the effective anisotropic surface energy (surface stiffness), and $K_{i j}$ is related to the local curvature of the interface. The interface is driven by the curvature contribution $\sigma_{i j}^{*} K_{j j}$ and by the thermodynamic driving force $\Delta G_{i j} . \Delta G_{i j}$, which is a function of the local composition $\rightarrow c$, couples the Phase-Field equations to the diffusion equations: 


$$
\dot{\vec{c}}=\nabla \sum_{i=1}^{N} \varphi_{i} \overrightarrow{D_{i}} \nabla \overrightarrow{c_{i}}
$$

where $\rightarrow D_{i}$ is the multicomponent diffusion coefficient matrix for phase $\iota . \rightarrow D_{i}$ is calculated online for the given concentration and temperature using the Fortran $\mathrm{TQ}^{\circledR}$ interface to Thermo-Calc ${ }^{\circledR}$ and the mobility databases MOB2 [22]. In case of recrystallization modelling the thermodynamic driving force is replaced by stored energy.

\section{Input parameters}

2D-Modelling The performed 2D-Phase-Field simulation is carried out based on the real microstructure of cold-rolled steel, Figure 3. Here, the left image represents the nital-etched micrograph of the cold-rolled sample, where the ferrite is bright and pearlite and grain boundaries are dark. The centre image shows the phase arrangement reproduced by simulation software. The size of this $2 \mathrm{D}$-simulation domain is about $110 \times 80 \mu \mathrm{m}^{2}$. Similar to the nital-etched micrograph, in the replicated pattern, ferrite is white while pearlite and grain boundaries are black. The right image shows the carbon distribution in black-and-white scale, wherein black corresponds to zero and white to the maximum carbon concentration 0.7 wt.- $\%$.

There, the important material characteristics, i.e. distribution of alloying elements and stored energy, are taken from the microprobe and EBSD analyses. In the simulation $\mathrm{C}, \mathrm{Si}, \mathrm{Mn}$ and $\mathrm{Cr}$ were included, which are the main alloying elements in this DP600 grade. Thus, according to the microprobe results, it is taken that the substitutional elements are homogeneously distributed in the structure whereas the carbon content in pearlite is about $0.60 \mathrm{wt} .-\%$ and in ferrite $0.002 \mathrm{wt.} . \%$.

The stored energy of ferritic grains which is the driving force for the recrystallisation is set between 3 and $7 \mathrm{~J} / \mathrm{cm}^{3}$, so that the average value corresponds to the EBSD results. As pearlite is a much harder phase compared to ferrite, the stored energy of pearlite is set to zero and thus, recrystallisation occurs only in ferrite and is finalised before austenite forms.

Recrystallisation is followed by the nucleation and growth of new grains. Due to the high heating rate in industrial annealing lines, recovery has been neglected in this study. Additionally to the stored energy, which is the driving force for this process, the

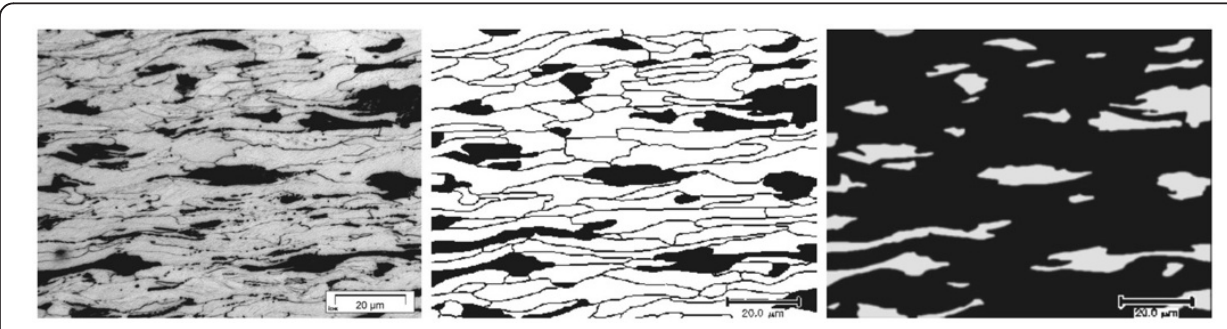

Figure 3 Nital-etched micrograph of the cold-rolled sample (left), phase arrangement reproduced by simulation software (center) and representation of carbon distribution in black-and-white scale (right). 
main input parameters for the simulation of recrystallisation are nucleation density and grain boundary mobility. These parameters determine the rate and characteristics of the whole process.

To approximate the real transformation behaviour, 2D-simulation of recrystallisation is performed following a local maximum stored energy criterion assuming continuous nucleation. The reason for this is the fact that in the 2D-simulations each grain emerging on the simulated surface should be assumed to be a newly-generated. Thus, for the 2D-modelling it is important during the whole process to introduce new grains which reflect and compensate growth of grains from the underlying level in the considered 2D-section. The total number of nuclei appearing during the simulation is set to 250 based on the experimental grain size distribution after recrystallisation. This approach is similar to that used by [23] combining nucleation scenario assumptions with mobility adjustment to replicate the experimental data.

The grain boundary mobility is typically given by the Arrhenius equation describing its temperature dependence. The activation energy for $\alpha / \alpha$ grain boundary mobility is fixed to $140 \mathrm{~kJ} / \mathrm{mol}$ as this is the most widely used value in the literature [24]. The preexponential factor is set to $3.2 \times 10^{-6} \mathrm{~m}^{4} /(\mathrm{Js})$ based on the comparison of the simulated growth of the single grains by the variation of the pre-exponential factor with the experimental grain sizes. As the simulation focuses on micro scale, all grain boundaries are assumed to be high angle grain boundaries and will be kinetically treated identically.

The modelling of phase transformation (austenite formation from ferrite pearlite and ferrite formation from austenite) will be performed separately and the results will be combined in one through process simulation. For the simulation of pearlite dissolution a simplified approach is used. Pearlite in this approach is considered as an effective pseudo-phase with mixed properties of ferrite and cementite. The thermodynamic driving force for dissolution is calculated from overheating obtained by a linearization of the phase diagram. The interactions of pearlite with other phases are defined by assumed slopes which restrict the two phase regions [13]. Based on the metallographic observations, nucleation of austenite during heating is assumed to take place only within pearlitic grains. The number of austenite nuclei is set to 100 so that in the large pearlitic grains several austenite nuclei could form, similar to the metallographic finding.

The thermodynamic driving force for the modelling of ferrite-to-austenite and austenite-to-ferrite transformations is obtained by the direct coupling to the thermodynamic database via the Gibbs energy minimisation software Thermo-Calc ${ }^{\circledR}$. The modelling of these phase transformations are performed taking into account redistribution of substitutional alloying according to LENP (Local Equilibrium Non Partitioning) conditions using special model for solute redistribution [12].

The diffusion parameters are taken from the kinetic database MOB2. The mobility for the ferrite/austenite and pearlte/austenite grain boundaries are defined by an activation energy, of $140 \mathrm{~kJ} / \mathrm{mol}$ and a pre-exponential factor of $1.5 \times 10^{-6} \mathrm{~m}^{4} /(\mathrm{Js})$. The other input parameters which have to be mentioned here are interfacial energy the interfacial energy $\sigma_{i j}^{*}$, of $0.4 \mathrm{Jm}^{-2}$ for ferrite/austenite interface, $0.9 \mathrm{Jm}^{-2}$ for austenite/pearlite interface, $0.7 \mathrm{Jm}^{-2}$ for austenite/austenite interface [13], the grid spacing $\Delta x$, which is taken to be $0.2 \mu \mathrm{m}$, and the interface thickness $\eta$, which in this work equals to $1 \mu \mathrm{m}$. 
3D-Modelling Due to the fact that a 3D-simulation demands high computational capacity as well as being very time consuming, a small simulation domain of $30 \times 30 \times 30$ $\mu \mathrm{m}^{3}$ is selected for 3D-simulations of microstructure evolution during processing of cold-rolled dual-phase steel. Figure 4 shows this created structure consisting of about $16 \%$ of pearlite in a ferritic matrix as a 3D-volume domain. Again, in this representation ferrite is white, while pearlite as well as the grain boundaries are black.

However, the direct comparison of 3D-structures with experimental data is hindered due to the fact that grain size distribution obtained from the volume element and from the surface of the same structures could be very different [25-27]. For the comparison of the simulated 3D- and 2D-structures the 3D-volume element has been be subjected to a series of cuts in order to get sufficient cumulative area of 2D-cuts. Figure 5 shows nine 2D-cuts of the 3D-volume presented in Figure 4 and comparison of the obtained ferrite grain size distribution with experimental data from EBSD-analysis.

The grain size distribution of the created volume domain obtained from the XYsections reflects an elongation of the real microstructure due to cold-rolling. Moreover, the ferrite grain size distribution of 3D-structure obtained from 2D-cuts is in fair correlation with the experimental data. The average grain size of created 3D-structure equals to $11.5 \mu \mathrm{m}$ and diverges only by $2-3 \mu \mathrm{m}$ from the experimentally-obtained grain size value $8.6 \mu \mathrm{m}$.

As in the case of 2D-structure, the content of alloying elements is taken according to the microprobe results and the stored energy of ferritic grains in the created 3Dstructure is set corresponding to the EBSD results. Most simulation parameters such as behaviour of substitutional alloying elements, mobility, interfacial energy and diffusion parameters are taken from 2D-approach. However, the nucleation parameters are adjusted due to the fact that continuous nucleation proposed for 2D-simulations assumes not only nucleation of new grains but also the growing up of grains from neighbour level. This is therefore not suitable for $3 \mathrm{D}$-simulations. Thus, it was established that the site saturation nucleation is much more applicable for the 3D-modelling of recrystallisation due to the fact that according to the experimental data, recrystallisation under the investigated heating parameters takes only 20-30 s. In order to reflect the experimentally-obtained average grain diameter after recrystallisation, which is determined by the nucleation density, it is supposed that 50 nuclei form at $660^{\circ} \mathrm{C}$. The grain junctions and interfaces are addressed as probable nucleation sites. Considering austenite formation, as in the case of $2 \mathrm{D}$-simulation it is assumed that nucleation takes

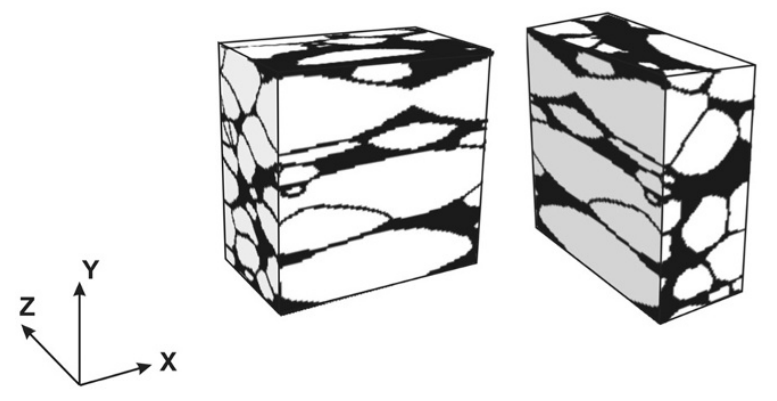

Figure 4 The generated initial structure for 3D-simulation. 


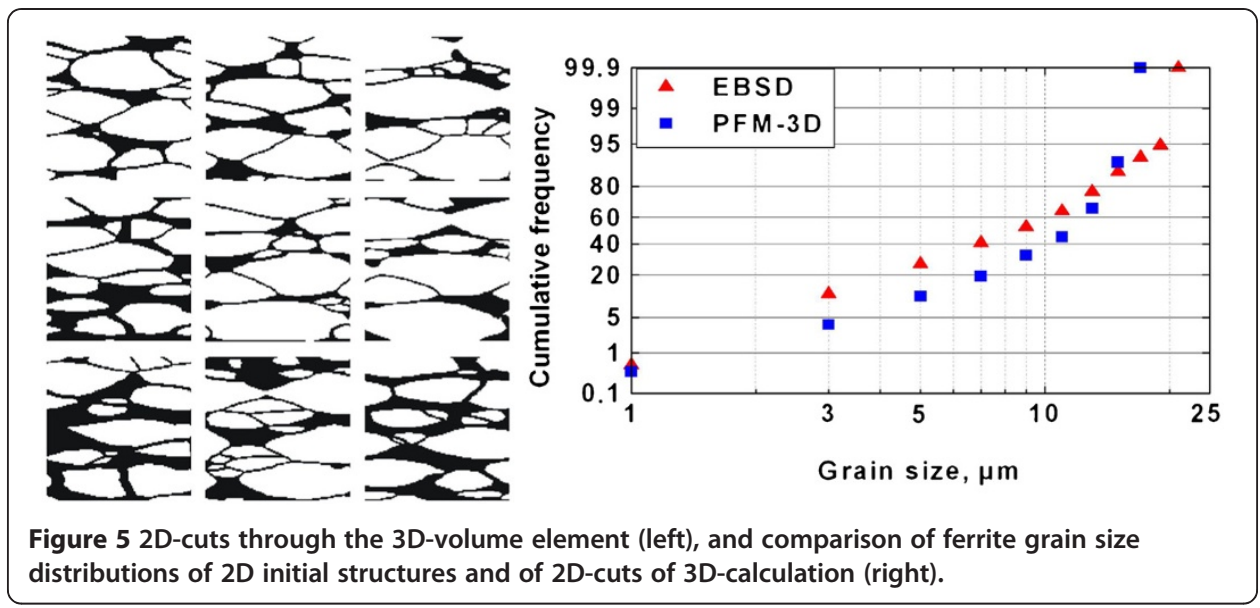

place only in pearlite. The number of nuclei is fixed to 25 so that in each pearlitic grain several austenite nuclei could form.

\section{Results and discussion}

In the following the results of the 2D- and 3D-modelling for the microstructure evolution during intercritical annealing with the process parameters according to Figure 2 will be presented.

Figure 6 represents 2D-simulated evolutions of transformed fractions. The data repeat quite well the experimental results for the same process conditions obtained by image analysis of corresponding micrographs. The analysis of the data shows that the evolution of transformed phase fractions during intercritical annealing as predicted by the 2D phase field simulation coincides with all experimental points.

The ferrite fraction predicted by the 3D-simulation during intercritical annealing with selected process parameters also reflects the experimental results quite well, Figure 7. The other phases are not shown in this diagram in order to keep the clearness in the representation. Beside the good agreement with the experimental data, evolution of the ferrite fraction from 3D-simulation reproduces well the 2D-resuts. Finally, the ferrite

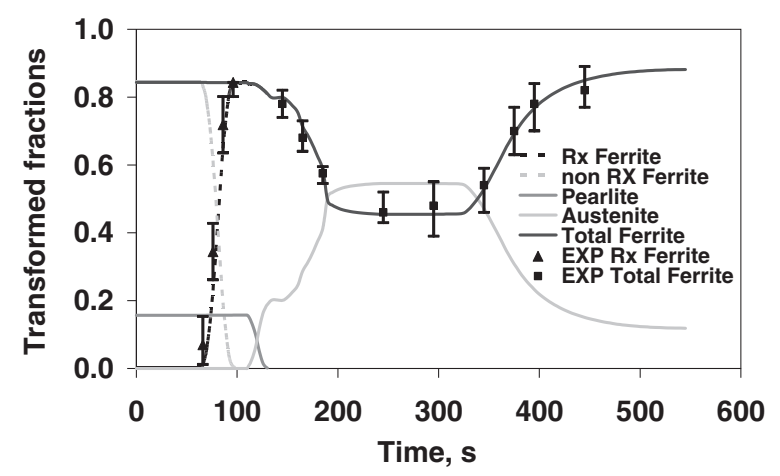

Figure 6 2D-simulation results for the through process kinetics of transformations compared with experimental data from interrupted dilatometer tests. 


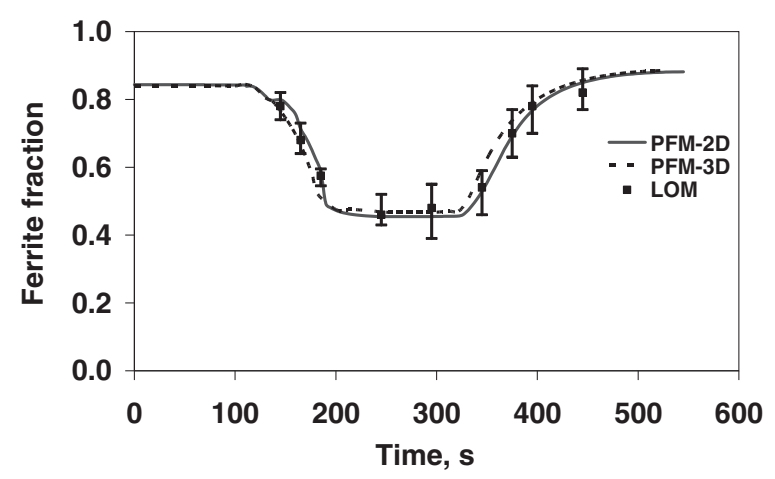

Figure 7 3D-simulation results for the evolution of the ferrite fraction evolution compared with 2Dresults and experimental data.

amount simulated in 3D and 2D is inside the scatter bars obtained by metallographic analysis.

The comparison of 2D- and 3D-simulated and experimental grain size distributions of ferrite after intercritical annealing is presented in Figure 8 at $650^{\circ} \mathrm{C}$. Both simulated grain size distributions matches the EBSD results quite well. Moreover, the average ferrite grain sizes at $650^{\circ} \mathrm{C}$ obtained from the $2 \mathrm{D}$ - and 3D-simulations versus experiment are $7.9 \mu \mathrm{m}, 9.8 \mu \mathrm{m}$ and $8.0 \mu \mathrm{m}$, respectively.

Mecozzi et al. have shown that the predicted ferrite grain size distribution depends in detail on the assumed nucleation behaviour [23]. Further, it is suggested that the apparent mobility in $2 \mathrm{D}$ is lower than in $3 \mathrm{D}$ to match a reference kinetics for a given nucleation scenario. In the present simulation $2 \mathrm{D}$ and 3D mobilities are the same, while in 2D continuous nucleation has been assumed and in 3D all nuclei form at the same temperature (site saturation). The apparent agreement of 2D and 3D mobilities might be accepted to be a compensation effect of 2D vs. 3D growth geometries and increased nucleation spread in 2D as compared to 3D simulations.

For the more efficient evaluation of modelling results, the quality of the phase transformation simulation is verified by comparing micrographs and simulated microstructures at selected temperatures following cycle from Figure 2. Figure 9 represents the micrographs and outputs from $2 \mathrm{D}$-simulation at $710^{\circ} \mathrm{C}$ (after recrystallization), $800^{\circ} \mathrm{C}$ (heating to intercritical temperature) and $650^{\circ} \mathrm{C}$ (subsequent cooling after intercritical

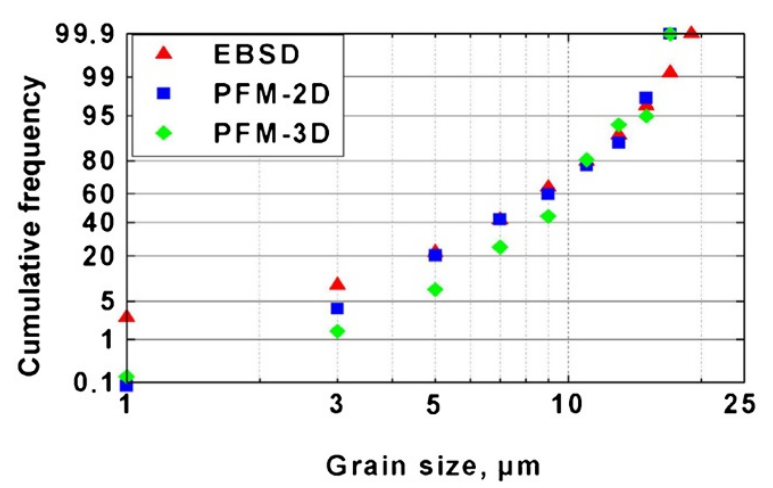

Figure $82 \mathrm{D}$ - and 3D-simulation results for the ferrite grain size distribution at $650^{\circ} \mathrm{C}$ compared with the experimental data from EBSD analysis. 


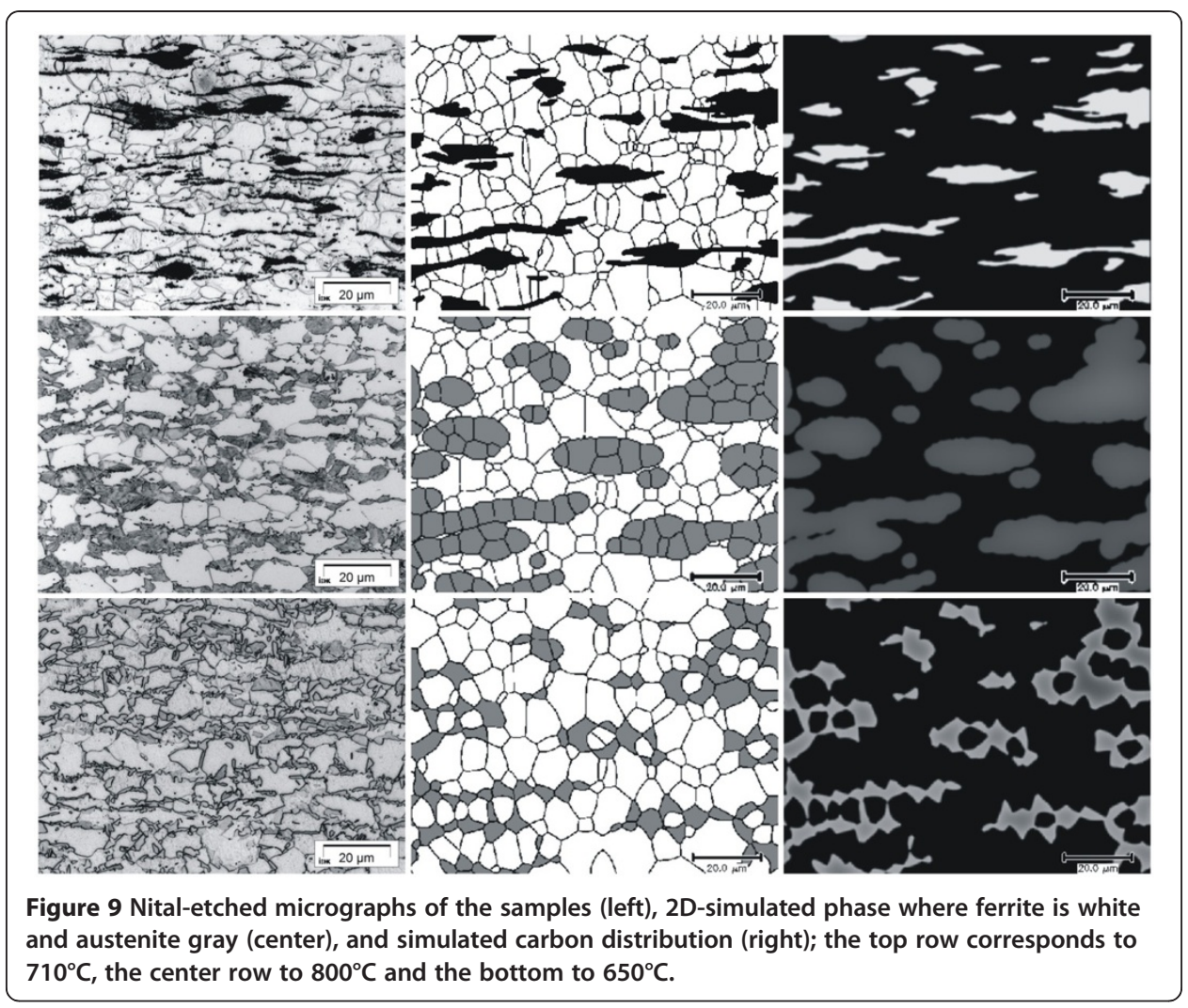

annealing). The left images represent micrographs of the nital-etched samples interrupted at the corresponding temperatures and quenched to Room temperature. In these micrographs, ferrite is bright, and martensite (which is assumed to have been austenite before quenching) as well as grain boundaries are dark. The central and right images represent simulated phase and carbon distribution; here the same colour scale is used as in Figure 1.

The visual comparison of the phase distributions and the grain sizes at $710^{\circ} \mathrm{C}$ shows that 2D-results are quite similar with real micrograph. Both, metallographic and simulation results show that the recrystallisation has been completed. At corresponding temperature the deformed elongated ferritic grains are substituted by the round recrystallized grains. Nvertheless, there is still room for improvement. One aspect that is not considered in the simulations is banding due to segregation effects that is quite obvious from the micrograph shown in Figure 1.

At $800^{\circ} \mathrm{C}$, the calculated austenitic fraction is about $41 \%$, which agrees with the experimentally observed $42 \%$. The grain distributions in the simulated structure and in the micrograph are similar. An elongated arrangement of phases can be observed in both as a result of the stretched arrangement of pearlite in the initial structure. Due to the fact that the ferrite to austenite phase transformation is controlled by carbon diffusion, a redistribution of carbon during the progress of phase transformation occurs. At this temperature, the austenite contains about 0.24 wt.-\% carbon.

The simulated structure at $650^{\circ} \mathrm{C}$ with about $77 \%$ of ferrite and $23 \%$ of austenite also corresponds well to the real dual-phase microstructure. The experimental results with 
$78 \%$ of ferrite and $22 \%$ of martensite confirm the simulation. Although the phase arrangement and distribution of ferritic grains in both structures are very similar, the network of austenitic/martensitic grains in the simulated structure seems to be somewhat coarser. This could be a consequence of the fact that the final dual-phase microstructure still reflects the initial distribution of pearlite. Though the performed simulation based on the real micrograph, very small pearlitic grains (smaller than 3 grid element) have not been reproduced in the starting structure. The absence of these grains may lead to the somewhat coarser martensite network in the final simulation structure.

The carbon distribution map shows the enrichment of carbon fraction in the remaining austenite with decreasing austenite fraction. The average carbon concentration in the austenite at $650^{\circ} \mathrm{C}$ reached a value of about $0.41 \%$.

Figure 10 shows the phase and carbon distributions at $710^{\circ} \mathrm{C}, 800^{\circ} \mathrm{C}$ and $650^{\circ} \mathrm{C}$ predicted by the $3 \mathrm{D}$-simulation with the same colour scale as in the 2D-results in Figure 9. As mentioned above, the size of ferritic grains from 3D-simulation in general agree 2Dresults and experimental data, Figure 10. The 3D-results concerning phase arrangement, seem to be similar to the 2D-simulation and experimental data as well. Moreover, the average carbon concentration in the austenite at $650^{\circ} \mathrm{C}$ according to 3Dresults is about 0.46 wt.- $\%$ that also matches $2 \mathrm{D}$-simulation result.

\section{Outlook}

From the information of the carbon content in austenite, the $M_{s}$-temperature at each point of structure can be calculated. Thus, from the structure simulated by means of Phase-Field Method, ferrite-martensite structure can be obtained by the application of Koistinen-Marburger [28] or an alternative approach. This will enable coupling to the already available models for the modelling of mechanical properties, such as for example RVE-FE Method for the prediction of flow behaviour [29-31].

\section{Conclusions}

2D- and 3D-simulations of microstructure evolution during processing of dual-phase steels from cold-rolled strips have be realized by means of Phase-Field Modelling approach. It allows to describe all metallurgical phenomena occurring on a microstructural

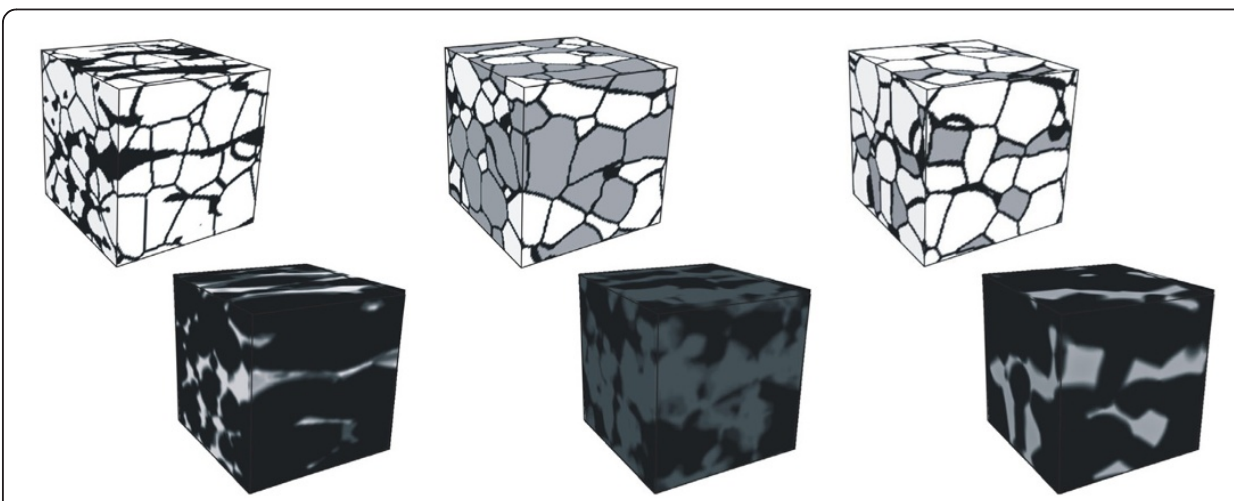

Figure $103 \mathrm{D}$-simulated phase distributions (top row) at $710^{\circ} \mathrm{C}$ (left), $800^{\circ} \mathrm{C}$ (center) and $650^{\circ} \mathrm{C}$ (right) where pearlite is black, ferrite white and austenite gray, carbon distributions at corresponding temperatures (bottom). 
scale during intercritical annealing, i.e. recrystallisation, austenite formation, ferrite formation as a function of chemical composition, starting microstructure and process parameters. The accurate definition of input model parameters yields both 2D- and 3Dapproaches to simulate the microstructure evolution successfully. The comparison of 2D- and 3D-simulated results with experimental data demonstrates an overall agreement of the predicted evolution of phase fraction and grain size distribution.

Moreover, evolution of carbon distribution, especially the carbon distribution in the final structure, is an important output of Phase-Field simulations. Carbon dissolved in martensite determines its hardness, and therefore, mechanical properties of the investigated steel. This can be used for the following prediction of the microstructure evolution. It will allow determining martensite start temperature in case of the subsequent quenching as well as further modelling of flow behaviour of material.

The advantage of $2 \mathrm{D}$-simulation compared to the $3 \mathrm{D}$-approch is the achievement of fast results and directly comparison with experimental data enabling rapid revelation of the influencing parameters. Therefore it can be utilised for the optimisation of process parameters to achieve the essential microstructure. In contrast, the 3D-simulations are much more time-consuming and need high computational capacity but can be applied easily for the following coupling with the models for the prediction of mechanical properties.

\section{Competing interests}

'The author(s) declare that they have no competing interests.

\section{Author's contributions}

JR did the experiments, the calculations and prepared the first version of article text. UP discussed and analysed the experimental and simulation results, contributed during text and figure preparation and corrected the article. WB analysed and discussed the final results and conclusions and the article text. All authors read and approved the final manuscript.

\section{Acknowledgement}

This research was carried out under project number MC5.06257 in the framework of the Research Programme of the Materials innovation institute M2i (www.M2i.nl). The authors acknowledge the financial support of M2i as well as the fruitful discussion with Henk Vegter, Piet Kock (both now at Tata Steel Europe) and Jilt Sietsma.(Delft University of Technology).

Received: 4 July 2012 Accepted: 6 August 2012

Published: 31 August 2012

References

1. Bag A, Ray KK, Dwarakadasa ES (1999) Influence of martensite content and morfology on tensile and impact properties of high-martensite dual-phase steels. Metallurgical and Materials Transactions 30A 5:1193-11202

2. Tomita Y (1990) Effect of morphology of second-phase martensite on tensile properties of Fe-0.1C Dual-phase steels. Journal of Materials Science 25:5179-5184

3. Militzer M, Poole WJ (2004) A critical comparison of microstructure evolution in Hot-rolled and cold-rolled dualphase steels. AHSSS Proceedings :219-229

4. Huang J (2004) Microstructure evolution during processing of dual phase and TRIP steels. PhD Thesis, University of British Columbia

5. Peranio et al (2010) Microstructure and texture evolution in dual-phase steels: competition between recovery, recrystallization, and phase transformation. Materials Science and Engineering A 527:4161-4168

6. Calcagnotto et al (2008) Ultrafine grained ferrite/martensite dual phase steel fabricated by large strain warm deformation and subsequent intercritical annealing. ISIJ International 48:1096

7. Calcagnotto et al (2011) and fracture mechanisms in fine- and ultrafine-grained ferrite/martensite dual-phase steels and the effect of aging. Acta Materialia 59:658-670

8. Bäker M (2002) Numerische methoden in der materialwissenschaft. Braunschweiger Schriften des Maschinenbaus 8, Braunschweig ISBN 3-936148-08-2

9. Raabe D, Roters F, Barlat F, Chen LQ (2003) Continuum scale simulation of engineering materials. Weinheim WileyVCH Verlag, Weinheim

10. National Research Council (2008) Integrated computational materials engineering: a transformational discipline for improved competitiveness and national security. National Academic Press, Washington D. C

11. Gottstein G (2007) Integral materials modeling. Weinheim Wiley-VCH-Verlag, Weinheim 
12. Rudnizki J, Böttger B, Prahl U, Bleck W (2011) Phase-field modelling of austenite formation from a ferrite plus pearlite microstructure during annealing of cold-rolled dual-phase steel. Metallurgical and Materials Transactions A 8:2516-2525

13. Thiessen RG (2006) Physically-based modelling of material responce to welding. PhD Thesis, TU Delft

14. Mecozzi MG (2007) Phase-field modelling of the austenite to ferrite transformation in steels. Ph.D Thesis, TU Delft

15. Militzer M (2011) Phase field modeling of microstructure evolution in steels. Current Opinion in Solid State and Materials Science 15(3):106-115

16. Zaefferer S, Konijnenberg P, Demir E, Woodcock T (2010) Progress in 3-dimensional EBSD-based orientation microscopy: New software tools for 3-dimensional materials characterization. Materials Science and Engineering MSE 2010, Darmstadt

17. Eshelby JD, Read WT, Shockley W (1953) Anisotropic elasticity with applications to dislocation theory. Acta Metallurgica 1:251-259

18. Steinbach I, Pezzolla F, Nestler B, Seeßelberg M, Prieler R, Schmitz GJ, Rezende JLL (1996) A phase field concept for multiphase systems. Physica D 94:135-147

19. Eiken J, Böttger B, Steinbach I (2006) MultiPhase-field approach for multicomponent alloys with extrapolation scheme for numerical application. Phys Rev E 2006:066122

20. Steinbach I (2009) Phase-field models in materials science; a tutorial review. Modelling and Simulation in Materials Science and Engineering 17:073001-31

21. MICRESS - The Microstructure Evolution Simulation Software http://micress.de

22. Thermo-Calc Software http://www.thermocalc.com

23. Mecozzi MG, Militzer M, Sietsma J, van der Zwaag S (2008) The role of nucleation behavior in phase-field simulations of the austenite to ferrite transformation. Metall Mater Trans 5:1237-1247, A 39

24. Krielaart GP, van der Zwaag S (1998) Simulations of pro-eutectoid Ferrite Formation using a Mixed Control Growth Model. Material Science and Engineering A246 1998:104-116

25. Giumelli AK, Militzer M, Hawbolt EB (1999) Analysis of the austenite grain size distribution in plain carbon steels. ISIJ International 39:271-280

26. Calcagnotto $\mathrm{M}$ et al (2010) Orientation gradients and geometrically necessary dislocations in ultrafine grained dual-phase steels studied by 2D and 3D EBSD. Mater Sc Engin A 527:2738

27. Zaefferer $S$ et al (2008) Three-dimensional orientation microscopy in a focused ion beam-scanning electron microscope: A new dimension of microstructure characterization. Metal Mater Trans A 39A:374-389

28. Koistinen DP, Marburger RE (1959) A general equation prescribing the extent of the austenite-martensite transformation in pure iron-carbon alloys and plain carbon steels. Acta Metallurgia 7:59-60

29. Rodriguez R, Gutierrez I (2004) Mechanical behaviour of steels with mixed microstructure. Proceeding of TMP'04, B-Liege 363:356-363

30. Thomser C, Uthaisangsuk V, Bleck W (2009) Influence of martensite distribution on mechanical properties of dual phase steels: experiments and simulation. Steel research international 80(8):582-587

31. Uthaisangsuk V, Prahl U, Bleck W (2009) Failure modeling of multiphase steels using representative volume elements based on real microstructures. Procedia Engineering 1(1):171-176

doi:10.1186/2193-9772-1-3

Cite this article as: Rudnizki et al:: Phase-field modelling of microstructure evolution during processing of coldrolled dual phase steels. Integrating Materials and Manufacturing Innovation 2012 1:3.

\section{Submit your manuscript to a SpringerOpen ${ }^{\circ}$ journal and benefit from:}

- Convenient online submission

Rigorous peer review

- Immediate publication on acceptance

- Open access: articles freely available online

- High visibility within the field

- Retaining the copyright to your article

Submit your next manuscript at $\boldsymbol{\nabla}$ springeropen.com 